\title{
Natural solutions: protected areas helping people to cope with climate change
}

\author{
Kathy MacKinnon, Nigel Dudem and Trevor Sandwith
}

The Aichi Targets agreed at the 1oth Conference of the Parties of the Convention on Biological Diversity at Nagoya, Japan, in 2010 lay out a roadmap and strategic plan to improve conservation and sustainable use of biodiversity by 2020. Target 11 specifically identifies the need to expand the number and area of protected areas to at least $17 \%$ of terrestrial and inland water habitats (from 12.7\%) and $10 \%$ of marine areas (from c. $1 \%$ ). A further 17 of the 20 targets are also related directly to the expansion and improved management of protected areas. Protected areas are the cornerstones of biodiversity conservation but generating support for more conservation areas will require stronger social and economic arguments to engender the political support to move fine words to effective action.

The main environmental issues in the coming decades will be climate change, water stress, food security, energy production and biodiversity loss. There is strong evidence that protected area systems can be effective tools for meeting these challenges by optimizing natural solutions in climate change response strategies. This potential will only be realized, however, if individual protected areas are well-managed and protected area systems are planned to maximize their role in protecting both biodiversity and ecosystem services.

Protected areas contribute to both mitigation and adaptation strategies by addressing the causes of climate change and helping societies to respond, and adapt, to the changes that are occurring. Mitigation includes both storagepreventing the loss of carbon already present in vegetation and soils-and capture of carbon by sequestering carbon dioxide from the atmosphere in natural ecosystems. Protected areas contribute to adaptation by protecting ecosystem resilience, buffering local climate and reducing risks and impacts from extreme events such as storms, floods, droughts and sea-level rise, and by providing and maintaining essential ecosystem services such as water supplies, fish stocks and other wild foods, and agricultural productivity (Dudley et al., 2009; World Bank, 2010).

Protected areas globally are estimated to contain at least $15 \%$ of the terrestrial carbon stock. Forests cover c. $30 \%$ of the world's land area but store $50 \%$ of terrestrial carbon, including soil carbon. Forest cover is often strikingly higher in protected areas, especially in indigenous reserves, than in surrounding lands (Dudley et al., 2009). Inland wetlands,

Kathy MaCKinNon (Corresponding author) and Nigel Dudley World Commission on Protected Areas, IUCN, Rue Mauverney 28, 1196, Gland, Switzerland. E-mail kathy.s.mackinnon@gmail.com

Trevor Sandwith Global Programme on Protected Areas, IUCN, Gland, Switzerland particularly peat, contain large carbon stores, as do grasslands, which are estimated to hold $10-30 \%$ of global soil carbon. With poor management, however, these habitats can easily become net sources of carbon; habitat loss and degradation are already responsible for c. $20 \%$ of annual carbon emissions. Coastal and marine habitats, especially salt marshes, mangroves, kelp and sea grass beds are also important carbon sinks, sequestering carbon more efficiently than terrestrial ecosystems of equivalent area (Laffoley \& Grimsditch, 2009).

Adaptation will become an increasingly important part of the development agenda (World Bank, 2010). Protected areas provide a practical contribution to climate change responses by safeguarding vital ecosystem services. Many protected areas are already legally designated, managed to maintain vegetation and biodiversity values, with recognized boundaries and dedicated staff. The ecosystem goods and services they provide will help to reduce vulnerability to climate change.

Consider water, one of the most basic human needs. Some natural forests (particularly tropical montane cloud forests and some older forests) increase total water flow. Even more important, forests, wetlands and habitats such as the paramos of Latin America help to maintain water quality. Around one-third (33 out of 105) of the world's largest cities, including Jakarta, Mumbai, New York, Sofia, Bogotá, Dar es Salaam, Melbourne and Sydney, receive a significant proportion of their drinking water supplies directly from protected forest areas.

As climatic events become more severe, natural habitats can help to reduce the impact of natural hazards and disasters. Protected, well-managed ecosystems, including forests and wetlands, can buffer many flood and tidal events, landslides and storms. Intact mangroves protect vulnerable coastal communities and reduce the damage caused by tsunamis and hurricanes. Integrating protection of natural riverine forests into flood management strategies has, for example, proven to be a cost-effective way to complement early-warning systems and infrastructure along the Parana River in Argentina, protecting rich biodiversity in the floodplains and human settlements (World Bank, 2010). Protected areas also contribute to long-term food security, providing downstream water supplies for agricultural fields and acting as natural reservoirs for wild crop relatives, medicinal plants, pollinators and pest control. Guanacaste National Park in Costa Rica, for example, benefits neighbouring citrus plantations through ecosystem services such as pollination, pest control and nutrient and water supply, 
services for which it receives payments. Marine and freshwater reserves provide safe havens for breeding to replenish and restore fish populations following overfishing or coral bleaching. Fish stocks in marine protected areas, as well as diversity and biomass, are higher than in surrounding seas, even after only 1-3 years of protection (Halpern, 2003).

How well protected areas deliver ecosystem services depends on how effectively they are managed. Protected areas exist under a range of management and governance regimes, from strict no-access areas to protected landscapes and indigenous reserves that include human settlements and cultural management. Consolidating, expanding, and improving the global protected area system is a logical response to both climate change and the crisis of biodiversity loss. Making protected areas a key part of national and local responses to climate change can help to reduce rates of deforestation, protect carbon-rich habitats, ensure more sustainable land management and increase the resilience of human communities, especially the poorest and most vulnerable. Achieving these multiple objectives requires the following actions:

(1) More and larger protected areas and buffer zones to improve ecosystem resilience, particularly in areas of high carbon and high biodiversity or where ecosystem services are under threat, such as in watersheds, tropical forests, peat, mangroves, freshwater and coastal marshes, and sea grass beds. (2) Connecting protected areas within landscapes/ seascapes to expand habitat under some form of conservation management beyond park boundaries in buffer zones, biological corridors, and ecological stepping-stones, to build connectivity and resilience to climate change. (3) Recognition and implementation of the full range of protected area governance types to recognize community-based governance systems and encourage stakeholders to establish, declare and manage protected areas as part of community climateresponse strategies. (4) Increasing the level of protection within protected areas to protect and manage specific features with high carbon storage values; for example, to maintain old-growth forest or avoid loss and degradation of wetland and peat habitats. (5) Improving management within protected areas to maintain conservation and carbon values and reduce degradation of habitats from threats such as illegal logging, agricultural encroachment, overexploitation, poor fire management and invasive alien species. (6) Restoration strategies to restore degraded habitats within protected areas and thus enhance carbon and biodiversity values.

While climate change increases the threats to biodiversity it also provides a unique opportunity to re-emphasize the multiple values of protected areas and the ecosystem services they provide. For too long these services have been regarded as free goods and rarely, if ever, acknowledged in national accounting. New initiatives such as the study on The Economics of Ecosystems and Biodiversity and the availability of substantial international finance for Reduced Emissions from Deforestation and Degradation of Forest (REDD+) are focusing attention on natural habitats. There is already much optimism but also debate about how REDD+ may benefit biodiversity conservation (Clements, 2010). Better protection of all natural ecosystems (not just forests) can contribute significantly to both mitigation of climate change and, even more importantly, adaptation to climate change. It is time to recognize, and reward, the key role of protected areas and other ecosystem-based approaches in national strategies to address climate change, and to emphasize that these are cost-effective, proven and sustainable solutions to complement cleaner energy strategies and improved infrastructure and technologies. Many protected areas can be justified on their socio-economic benefits alone. Promoting natural solutions to climate change and other global challenges should surely provide the justification for protected area expansion that many governments espoused at Nagoya.

\section{References}

Clements, T. (2010) Reduced Expectations: the political and institutional challenges of REDD+. Oryx, 44, 309-310.

Dudley, N., Stolton, S., Belokurov, A., Krueger, L., Lopoukhine, N., MacKinnon, K. et al. (2009) Natural Solutions: Protected Areas Helping People Cope with Climate Change. IUCN-WCPA, TNC, UNDP, WCS, the World Bank, and WWF, Gland, Switzerland, Washington, DC, and New York, USA.

HALPERN, B.S. (2003) The impact of marine reserves: do reserves work and does reserve size matter? Ecological Applications, 13, $117-137$.

Laffoley, D. \& Grimsditch, G. (eds) (2009) The Management of Natural Coastal Carbon Sinks. IUCN, Gland, Switzerland.

World BANK (2010) Convenient Solutions to an Inconvenient Truth: Ecosystem-Based Approaches to Climate Change. World Bank, Washington, DC, USA.

\section{Note from the Editor}

In December 2011 the International Congress for Conservation Biology will take place in Auckland, New Zealand. To mark the location of the Congress we have brought together in this issue a range of articles on conservation in Asia and Australasia. The theme of the Congress, Engaging Society in Conservation, is touched upon directly by the two lead articles, on market-based approaches to conservation governance (pp. 482-491) and the harvesting of the orange-headed thrush in Bali (pp. 492-499), and also by other articles, including those on participatory networks for monitoring (pp. 534-545) and jaguar conservation in a community-dominated landscape (pp. 554-560). 